\title{
O turismo comunitário na zona costeira do Ceará, Brasil
}

\author{
Community tourism in the coastal zone of Ceará, Brazil
}

\author{
Caroline Vitor Loureiro ${ }^{\mathrm{a}}$ \\ Adryane Gorayeb ${ }^{b}$
}

\begin{abstract}
${ }^{a}$ Professora do Instituto Federal de Educação, Ciência e Tecnologia do Ceará. Possui Graduação, Mestrado e Doutorado em Geografia pela Universidade Federal do Ceará. E-mail: caroline.loureiro@ifce.edu.br

${ }^{\text {b}}$ Professora Doutora do Programa de Pós graduação em Geografia, Universidade Federal do Ceará. E-mail: gorayeb@ufc.br
\end{abstract}

Recebido em: 24/03/2017 I Aceito em: 10/06/2017

ARTIGO

\begin{abstract}
RESUMO
O crescimento e expansão do setor turístico ocorreu no litoral cearense em áreas dotadas de elevado potencial paisagístico e já ocupadas por comunidades tradicionais pesqueiras e marisqueiras. Como mecanismo de resistência algumas comunidades optaram por associar suas atividades econômicas ao Turismo Comunitário. O Turismo Comunitário ou Turismo de Base Comunitária (TBC) é uma atividade que se contrapõe ao turismo de massa. Este serviço oferta práticas turísticas que aproximam o turista da cultura e dos ecossistemas da área receptora, atendendo a uma nova demanda turística que anseia por essa imersão nas atividades locais. Em seus princípios o TBC não substitui as atividades econômicas já existentes, ao contrário vem apresentar uma alternativa, mantendo as práticas tradicionais. Diante desse contexto, esse artigo objetiva analisar o desenvolvimento do Turismo Comunitário na zona costeira cearense e identificando seus benefícios para a economia da comunidade receptora, bem como mapear entidades de apoio e fomento às dificuldades enfrentadas. Para a realização do estudo foram visitadas três comunidades inseridas nas práticas do Turismo Comunitário: Tatajuba, localizada no município de Camocim; Curral Velho, localizada no município de Acaraú e Prainha do Canto Verde, localizada no município de Beberibe. As três comunidades fazem parte da Rede Tucum, que organiza e dá suporte às atividades de turismo comunitário a diversas comunidades cearenses. A pesquisa constatou que o turismo comunitário é uma boa alternativa financeira para qualificar a recepção dos turistas nessas comunidades e para possibilitar renda extra aos moradores locais, especialmente devido ao fato de agregar paisagens com natureza preservada à cultura local.
\end{abstract}

Palavras-chave: Turismo comunitário. Desenvolvimento. Zona costeira. Ceará. 


\section{ABSTRACT}

In the coast of Ceará the growth and expansion of the tourism sector occurred in areas with high potential for landscaping already occupied by traditional fishing and shellfish communities. As a resistance mechanism, some communities have chosen to associate their economic activities with Community Tourism. Community Tourism or Community Based Tourism is a modality that opposes mass tourism. This service offers tourist practices that bring tourists closer to the culture and ecosystems of the receiving area, meeting a new tourist demand that longs for this immersion in local practices. The principles of TBC does not replace the existing economic activities, on the contrary it presents an alternative, maintaining the traditional practices. In this context, this article aims to analyze the development of community tourism in the coastal zone of Ceará and to identify its benefits to the economy of the receiving community, as well as mapping entities of support and development to the difficulties faced.For the study, three communities with community tourism practices, Tatajuba, located in the municipality of Camocim;Curral Velho, located in the municipality of Acaraú and Prainha do Canto Verde, located in the municipality of Beberibe.These communities are part of the RedeTucum, which organizes and supports community tourism activities in various communities of Ceará. The research found that community tourism is a good financial alternative to qualify the reception of tourists in these communities and to provide extra income to local residents, especially due to the fact of adding landscapes with preserved nature to the local culture.

Keywords: Community tourism. Development. Coastal zone. Ceará.

\section{INTRODUÇÃO}

A demanda turística vem apresentando mudanças no que concerne à modalidade buscada. Observa-se que o crescimento dos meios urbanos, a homogeneização dos espaços de lazer nas cidades, o aumento dos níveis de estresse na população urbana e a busca da identidade cultural têm sido facilmente verificados como elementos que contribuem para a transformação das demandas humanas por turismo.

De acordo com Zaoual (2009), ao se avaliar as tedências mundias referentes ao turismo, observa-se que o turismo dito de massa não está mais totalmente em uso e que, também, não vem acompanhando a evolução das necessidades que o mercado exprime.

Para Tosun (2001) as políticas públicas de países em desenvolvimento baseiam-se, de forma geral, no fomento ao turismo de massa, dentro da necessidade de gerar recursos externos para financiar projetos de modernização nacional ou de equilibrar o balanço de pagamentos.

Nesse contexto, a globalização crescente tem proporcionado uma perda de referências, o que desencadeia, em contraponto, a necessidade de pertencimento, bem como de um intercâmbio intercultural.

Ciência e Sustentabilidade - Ces / Juazeiro do Norte, v. 3, n. 1, p. 58-73, jan/jun 2017 
Percebe-se nessa nova tendência, já reconhecida pelo mercado turístico, uma busca por atividades turísticas mais autênticas e que proporcionem a maior possibilidade de envolvimento e imersão na cultura local, bem como maior intercâmbio com os elementos da natureza.

As práticas buscadas diferem-se do turismo conhecido como turismo de massa, pois este negligenciou por meio da uniformização e padronização de sua oferta, a cultural dos locais receptores das atividades, bem como artificializou ambientes antes ditos naturais.

Diante desse contexto que Zaoual (2009) descreve como um mundo atormentado pela perda de referências,ganham destaque as relações desencadeadas pela necessidade de atender aosanseios da procura de sentidos, da parte dos atores, que lhes proporcionem a sensação de pertencimento, bem como de um intercâmbio intercultural.

Surge a necessidade de se incorporar outras dimensões, sobretudo a cultural e ambiental na prática turística. Como resposta a tal demanda, ocorreu a proliferação de novasconcepções na área particular do turismo, como turismo solidário, turismo intercultural, turismo da natureza, ecoturismo, turismo durável, turismo de proximidade,turismo de memória e de história, entre outros(ZAOUAL, 2009).

Este fato é comprovado pelos estudos conduzidos pela World Tourism Organization [WTO] (2012) que apresentam o Ecoturismo ${ }^{1}$, juntamente com o Turismo de aventura, crescendo mais de $20 \%$ ao ano, enquanto que o turismo considerado "mais tradicional" que aqui descrevemos como o turismo de massa, no qual a preocupação maior é simplesmente com o bem-estar dos turistas, apenas $7,5 \%$.

São demandas de turismo que buscam atividades que priorizem a proximidade dos ambientes que se diferem do meio urbano, uma busca por espaços ditos "naturais" e a imersão nas práticas culturais locais.

Em contraposição ao chamado turismo dos resorts e dos megaempreendimentos, e como forma de evitar que empreendedores externos

\footnotetext{
${ }^{1}$ Para Rodrigues (2003), uma atividade econômica, de baixo impacto ambiental, que se orienta para áreas de significativo valor natural e cultural, e que através das atividades recreacionais e educativas contribui para a conservação da biodiversidade e da sociodiversidade, resultando em benefícios para as comunidades receptoras.
} 
dominem as comunidades, surge o Turismo Comunitário ou Turismo de Base Comunitária (TBC), onde, em algumas comunidades litorâneas, apropriadas pelo processo de especulação imobiliária, representam a luta pela propriedade de terra litorânea (CORIOLANO et al., 2009). Tal prática vem atender também à demanda turística que se contrapõe ao turismo de massa e que anseia pelo contato com a cultura e ambientes nos locais visitados.

Ainda de acordo com a autora supracitada, o Turismo Comunitário é aquele em que as comunidades de forma associativa organizam arranjos produtivos locais, possuindo o controle efetivo das terras e das atividades econômicas associadas à exploração do turismo. Essa modalidade de turismo que de acordo com o Ministério do Turismo do Brasil - MTur (2010), data de meados da década de 1990, além de representar melhoria de renda para o grupo envolvido, proporciona a manutenção e proteção dos ecossistemas litorâneos, pois exerce práticas que valorizam a preservação dos ambientes através de uma lógica sustentável de desenvolvimento.

A transição para esse novo mercado, no entanto, passa a enfrentar os conflitos já associados ao turismo como, por exemplo,a especulação imobiliária eos impactos gerados sobre os ecossistemas, que no contexto turístico do estado do Ceará, destacam-se os litorâneos.

Coriolano (2009) destaca que o turismo na região Nordeste trouxe uma revalorização deste espaço no que se refere ao uso pelas práticas turísticas e de lazer, ampliando a disputa desse espaço para novos usos, e fazendo dele mercadoria imobiliária.

No estado do Ceará devido à crescente apropriação e conflitos pelo espaço litorâneo, resultado da reestruturação capitalista (CORIOLANO et al, 2009), tem sido potencializada a transformação do litoral do estado, valorizando os megaempreendimentos - parques eólicos, fazendas de camarão, construção de resorts - em detrimento das populações nativas.

O crescimento e expansão deste setor ocorreramno litoral cearense em áreas dotadas de elevado potencial paisagístico, já ocupadas por comunidades tradicionais pesqueiras e marisqueiras, que em sua grande maioria estão organizadas na forma de vilas, afastadas dos centros urbanos, e que ainda preservam antigas práticas culturais. 
Grandes empreendedores estrangeiros, aproveitando-se do desconhecimento da população residente nessas áreas, apoderaram-se de forma arbitrária desses territórios, assim como ressalta Coriolano (2009), ao discorrer acerca do processo de expansão do turismo no Ceará, exemplificando o ocorrido nas praias de Jericoacoara e Canoa Quebrada, respectivamente nos municípios de Jijoca e Aracati, onde,subsidiados por interesses externos, os territórios turísticos de maior expressão,de forma arbitrária e voltados às demandas internacionais, foram alvo de massiva presença de empreendedores estrangeiros fazendo submergir omercado turístico local.

O turismo se apresenta, portanto, como um vetor que estimula os processos de uso e ocupação do litoral, propiciando diferentes tipologias de apropriação. A zona costeira cearense, por meio do desenvolvimento do setor turístico, teve áreas naturais descaracterizadas e invadidas, colocando os moradores locais à margem dessa prática econômica.

No que se refere à relação políticas públicas e turismo comunitário, o Ministério do Turismo buscou atender essa demanda a partir de 1998 com o edital de chamada Pública de Projetos para seleção de propostas de apoio às iniciativas de TBC. De acordo com o Ministério do Turismo (2010), o edital atendia a demandas como: produção associada ao turismo; qualificação profissional; planejamento estratégico e organização comunitária; promoção e comercialização; e fomento às práticas de economia solidária. Foi neste edital que a Rede Tucum foi contemplada e recebeu apoio ao seu fortalecimento.

No entanto, não havia no estado ações de fomento ou apoio ao turismo comunitário. OPrograma de Desenvolvimento do Turismo - PRODETUR/CE ${ }^{2}$ que atendia o estado no mesmo período,não fazia nenhuma referência ao TBC, pois o programa era voltado para o desenvolvimento econômico do Estado por meio da organização de infraestruturas relacionadas ao turismo.

Partindo desta conjuntura que envolve a zona costeira cearense, sua apropriação pelo mercado turístico, as mudanças de demanda turística, e em contraposição, o surgimento do Turismo Comunitário, que além de responderà nova procura turística, fortalece a comunidade receptora por meio da inserção neste

\footnotetext{
${ }^{2}$ O PRODETUR/CE foi adotado em 1991 como uma política de desenvolvimento do turismo no litoral do Ceará, tendo como sustentáculo o PRODETUR/NE (DANTAS, 2006).
} 
serviço, percebemos a necessidade de se ampliar as discussões acerca da temática.

Este artigo objetiva, portanto, analisar o desenvolvimento do Turismo Comunitário na zona costeira cearense e avaliar seus benefícios para a economia da comunidade receptora, bem como verificar se recebem apoio ou orientação, e as dificuldades enfrentadas. Para a realização do estudo foram visitadas três comunidades inseridas nas práticas do Turismo Comunitário, Tatajuba localizada no município de Camocim, Curral Velho, localizada no município de Acaraú e Prainha do Canto Verde, localizada no município de Beberibe.

\section{METODOLOGIA}

Esse trabalho se caracteriza por seu caráter descritivo e discursivo, pois por meio da exemplificação de três casos de comunidades inseridas nas práticas do Turismo Comunitário, dialoga acercados benefícios e desafios que a participação dessa atividade proporciona aos envolvidos.

Para se alcançar os objetivos propostos por esse estudo, foram visitadas comunidades que estão vinculadas àRede Cearense de Turismo Comunitário - Rede Tucum (instituição que organiza, capacita e dá suporte às comunidades que têm interesse em exercer turismo de base local): Curral Velho, no município de AcaraúCE,Prainha do Canto Verde em Beberibe-CE e Tatajuba, no município de CamocimCE.

O critério de seleção para a escolha das três comunidades foi o fato de se inserirem em três diferentes contextos, o que diversifica a avaliação, pois no estado do Ceará, segundo dados da Rede Tucum,das quatorze comunidades praticantes do TBC, apenas duas não estãolocalizadas na zona costeira.

A Prainha do Canto Verde possui seu território inserido em uma unidade de conservação de uso sustentável, a Reserva Extrativista da Prainha do Canto Verde. Tatajuba se insere em uma Área de Proteção Ambiental (APA) criada por decreto municipal, a APA da Tatajuba, e Curral Velho, embora esteja em área de apicum que não é considerada Área de Preservação Permanente (APP), possui estreita relação com o ecossistema manguezal, tendo atividades econômicas relacionadas a este ambiente de APP. 
Nas visitasàs comunidades foram feitas entrevistas semiestruturadas commoradoresenvolvidos no desenvolvimento do TBC de cada comunidade, onde se discutiu questões como: as motivaçõesparase inserirem nesta prática; os benefícios socioambientais identificados; dificuldades enfrentadas; a percepção ou não de resistência pelo restante da Comunidade; a existência de apoio governamental e/ou não-governamental; entre outras.

As visitas também proporcionaram a imersão nas práticas ofertadas pelo TBC, bem como o reconhecimento da realidade local.

Para a contextualização, fundamentação e compreensão da temática realizou-se levantamento bibliográfico sobre o TBC, sobretudo, por meio de publicações disponibilidades pelo Portal Periódicos CAPES e sites institucionais de apoio a Turismo Comunitário.

A construção desse estudo possibilitou, portanto, uma reflexão e avaliação de como as atividades de Turismo Comunitário podem contribuir como mecanismo de resistência e fortalecimentodas comunidades situadas na zona costeira cearense.

\section{O TURISMO COMUNITÁRIO DE CURRAL VELHO (ACARAÚ), PRAINHA DO CANTO VERDE (BEBERIBE) E TATAJUBA (CAMOCIM): A DINAMIZAÇÃO DAS ATIVIDADES ECONÔMICAS LOCAIS}

A ocupação dazona costeira cearense pelo turismo se deu, em geral, sem a participação das comunidades já habitantes dessas áreas. Estas não interagiram com o turismo, sendo excluídos e explorados pelos agentes dessa atividade.

Coriolanoet al (2009) ressalta que a atividade turística vem se instalando no território cearense por meio do capital global e na forma de grandes empreendimentos. Tal característica evidencia que os moradores locais não são atores participantes desse processo, pois o mesmo apresenta uma lógica exclusiva e segregadora.

No entanto, com as mudanças de demanda do mercado turístico, buscando um turismo que aproximasse o turista da cultura, práticas sociais e meio ambiente das áreas receptoras, comunidades da zona costeira cearense passaram a associar suas atividades ao turismo, e sobretudo, utilizando-se disso como mecanismo de defesa de seus territórios e diversificando a economia local. 
É importante ressaltar que nessa prática de turismo, os moradores locais são atores do processo, atuando diretamente na oferta do serviço, valorizando seus espaços e reforçando o domínio sobre seus territórios, caracterizando-se por uma oferta de turismo associada aos moldes do Turismo Comunitário.

$\mathrm{Na}$ contramão do turismo global, comunidades litorâneas que muitas vezes serviram apenas de receptoras desse turismo, passaram a procurar se organizar e descobrir novos caminhos para entrarem nessa cadeia produtiva do turismo (CORIOLANO, 2003).

Pautados na lógica da sustentabilidade, preservação e manutenção do meio ambiente, o Turismo de Base Comunitária (TBC), modalidade de turismo datada de meados da década de 1990 (MTur, 2010), vem atendendo a essa demanda.

No ano de 1998 por meio de um edital de chamada Pública de Projetos o Ministério do Turismo abriu seleção de projetos de apoio às iniciativas de TBC (LOUREIRO \& GORAYEB, 2013), no qual a Rede Tucum foi contemplada e recebeu apoio ao seu fortalecimento.

A Rede Tucum é uma articulação formada por grupos de comunidades que realizam o turismo comunitário no Ceará, buscando a mobilização pela garantia dos territórios tradicionais dessas populações com justiça socioambiental e autonomia econômica. É composta por 14 experiências de Turismo Comunitário, sendo dozedistribuídas no litoral (Assentamento Coqueirinho em Fortim, Assentamento Maceió em Itapipoca, Batoque e Jenipapo-Kanindé em Aquiraz, Caetanos de Cima em Amontada, Curral Velho em Acaraú, Ponta Grossa e Tremembé em Icapuí, Prainha do Canto Verde em Beberibe, Tatajuba em Camocim, Tapeba em Caucaia eVila da Volta em Aracati) e duas na capital Fortaleza (Centro de Formação Frei Humberto - MSTe Conjunto Palmeiras).

O TBC, além de representar melhoria de renda para o grupo envolvido, proporciona a manutenção e proteção dos ecossistemas litorâneos, pois exerce práticas que valorizam a preservação dos ambientes através de uma lógica sustentável de desenvolvimento.

López-Guzmán, Borges e Castillo-Canalejo (2011) consideram que o Turismo Comunitário se apresenta como uma alternativa aos tradicionais destinos turísticos. Esta modalidade de turismo permite um maior contato com a comunidade e proporciona novas experiências para os vilarejos. 
Tratando-se dessa temática, o Ministério do Turismo se refere a indivíduos de uma comunidade que se reúnem para produzir de forma diferenciada, buscando alternativas de sobrevivência econômica por meio da atividade turística, aliada a fatores como a valorização do modo de vida da cultura e/ou a defesa do meio ambiente (MTur, 2010).

Na vertente ambiental, o TBC tem auxiliado na manutenção dos componentes geomorfológicos (planície fluvial, campo de dunas, planície litorânea etc.) nos quais se assentam as comunidades receptoras do turismo, por meio das ações de conscientização acerca da preservação da vegetação, fundamental para se evitar os processos erosivos e de assoreamento.

Tratando-se da vertente socioeconômica, é importante ressaltar que o Turismo Comunitário promove a produção, a distribuição e o consumo, de forma solidária, apontam o caminho para o desenvolvimento dos pequenos lugares, onde as pessoas se conhecem, se ajudam, podem ser solidárias e realizar atividades produtivas (CORIOLANO, 2003).

Nesse sentido as Comunidades de Curral Velho, Prainha do Canto Verde e Tatajuba (Figura 1), participantes da Rede Tucum, promovem o Turismo Comunitário

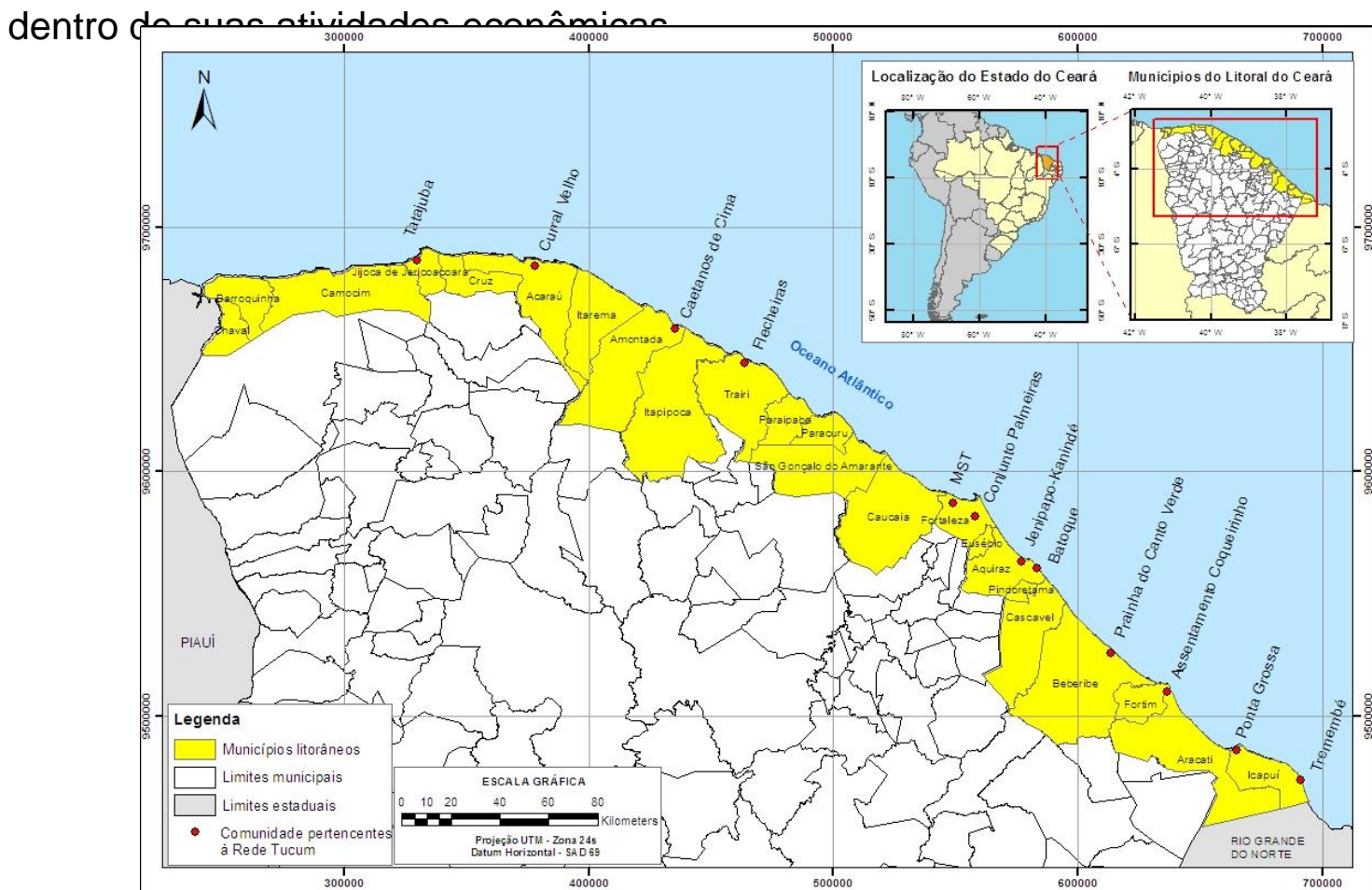

Figura 1: Mapa de localização das Comunidades pertencentes à Rede Tucum. Elaborado pela autora. Fonte dados: Rede Tucum. 
No setor de estuário da bacia hidrográfica do rio Acaraú, litoral oeste do Ceará, distante aproximadamente $250 \mathrm{~km}$ da capital Fortaleza, se localiza a Comunidade de Curral Velho. Com aproximadamente 3000 habitantes, a Comunidade está inserida em uma área de mangue utilizada como local para a realização de atividades de subsistência como a pesca e a mariscagem. Écaracterizada como Comunidade Tradicional de pescadores e marisqueiras com estreita relação com os ambientes naturais.

A comunidade da Prainha do Canto Verde localiza-se no muncípio de Beberibe, distante $30 \mathrm{~km}$ da sede municipal e cerca de $126 \mathrm{~km}$ de Fortaleza, e possui uma média de 1500 habitantes. Sua economia está basicamente relacioanda à pesca e agricultura de subsistência.Se caracteriza por seu histórico de lutas em defesa do território.

Localizada no distrito de Guriú, município de Camocim, distante $362 \mathrm{~km}$ de Fortaleza, e inserida em área de dunas, está a comunidade de Tatajuba. Com aproximadamente 150 famílias, a pesca artesanal e a agricultura de subsistência são a base de sua economia. Tatajuba não se difere das comunidades citadas anteriormente, marcada, também, por conflitos fundiários.

O intenso histórico de lutas refrentes à manutenção da posse de seus teritórios disputados por especuladores imobiliários mobilizousuas populações a organizarem-se em associações (Figura 2 e 3 ).

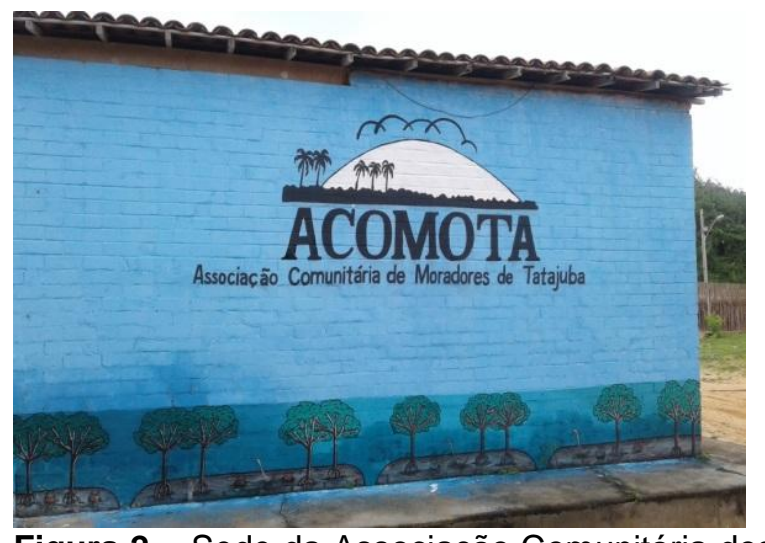

Figura 2 - Sede da Associação Comunitária dos Moradores da Tatajuba, Camocim-CE (ACOMOTA). Foto: Loureiro, 2017.

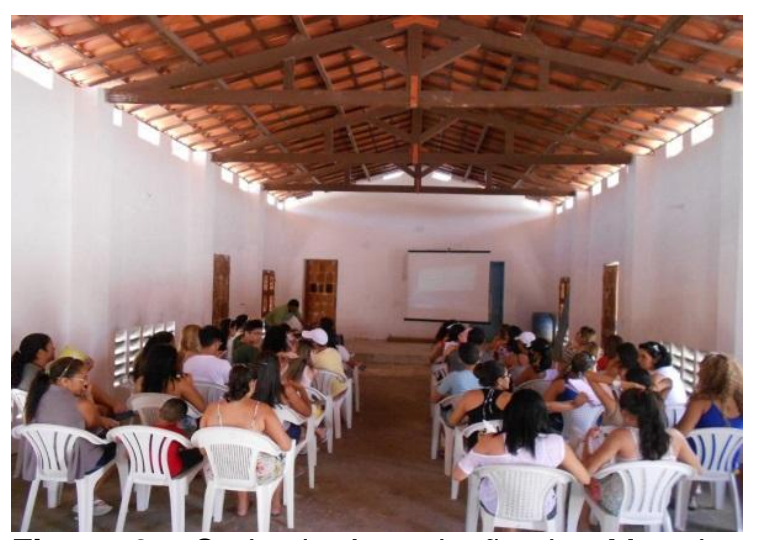

Figura 3 - Sede da Associação dos Moradores da Prainha do Canto Verde, Beberibe-CE. Foto: Loureiro, 2016.

Nas três comunidades aqui apresentadas o Turismo Comunitário enquadra-se na concepção do turismo sustentável, pois busca a oferta das práticas do turismo 
em conformidade com os potenciais e limitações dos ecossistemas em que se localizam.

O turismo comunitário aparece como uma alternativa, onde a partir da própria lógica da comunidade, busca que todos os ganhos financeiros permaneçam no local, tornando os investimentos um diferencial para o próprio desenvolvimento da comunidade, não apenas uma oportunidade de acumulação para o investidor que veio de fora (CAMURÇA, 2003).

A proposta do Turismo Comunitário nessas comunidades motivaa manutenção de práticas econômicas já existentes, buscando assim o fortalecimento da pesca e das atividades tradicionais, pois estas atividades é que são os atrativos turísticos.

É importante ressaltar, como avaliaCoriolano et al (2009), que é muito forte a consciência de que o turismo deve ser apenas um complemento à vida econômica da comunidade, portanto as atividades tradicionais como a pesca artesanal, a arte de fazer renda e a cultura do mar devem ser fortalecidas e incentivadas para que não sejam substituídas pelo padrão urbano e o consumismo.

Como forma de orientação às práticas desenvolvidas nessas três comunidades inseridas no TBC, a Rede Tucum elaborou em 2013 o Caderno de Normas e Procedimentos Internos. O caderno traz um conjunto de acordos e procedimentos coletivos baseados nos princípios políticos, que orientam a prática do TBC. De acordo com Martins (2013) trata-se de um instrumento adotado por livre iniciativa dos Grupos de Turismo Comunitário participantes da Rede, e que se comprometem a cumpri-lo integralmente.

Para atender ao Turismo Comunitário as comunidades de Curral Velho, Prainha do Canto Verde e Tatajuba ofertam serviços e atividades em conformidade com suas características culturais, ambientais e socioeconômicas.

Em Curral Velho, com a possibilidade do desenvolvimento do TBC, alguns equipamentos já existentes passaram a exercer novas funcionalidades, como o Centro de Educação Ambiental e Turismo Comunitário de Curral Velho, que atualmente funciona não apenas como local de reuniões, palestras, oficinas e encontros, mas como lugar para hospedagem de turistas e pesquisadores interessados na preservação do ecossistema. Em março do ano de 2012 foram construídos dois novos chalés para atender a demanda de visitantes no local (Figura 4). 
$\mathrm{Na}$ Prainha do Canto Verde a oferta de hospedagens (Figura 5) é feita na casa de moradores, chalés (Chalé Coqueiral e Casa Redonda) e pousadas (Pousada Refúgio da Paz e Pousada Sol e Mar).

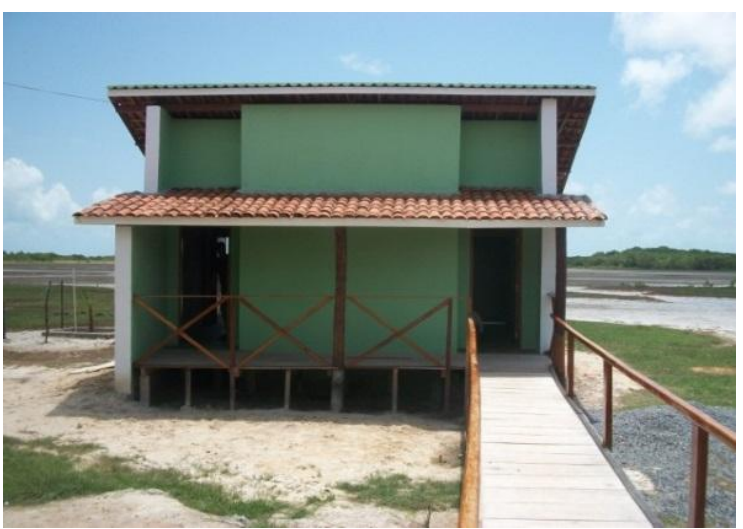

Figura 4 - Chalé do TBC em Curral Velho, Acaraú-CE. Foto: Loureiro, 2015.

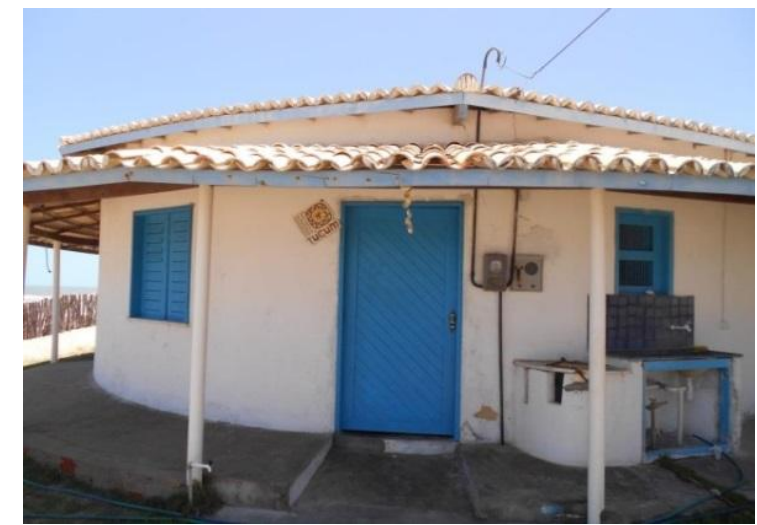

Figura 5 - Chalé Casa Redonda na Prainha do Canto Verde, Beberibe-CE. Foto: Loureiro, 2016.

A oferta de hospedagem em Tatajuba ocorre em chalés (Chalé do Coração, Chalé Sol Nascente e Chalé Duna Encantada) e na sede da Associação Comunitária dos Moradores da Tatajuba (ACOMOTA).

Dentre algumas das práticas desenvolvidas pela comunidade de Curral Velho destacam-se a realização de trilhas ecológicas no manguezal e gamboas (Figura 6), passeio de barco pelo mar e, também, manguezal, todos com vistas às práticas de educação ambiental para os turistas.

$\mathrm{Na}$ Prainha do Canto Verde podemos destacar as trilhas ecológicas e 0 passeio de buggy nas dunas (Figura 7).

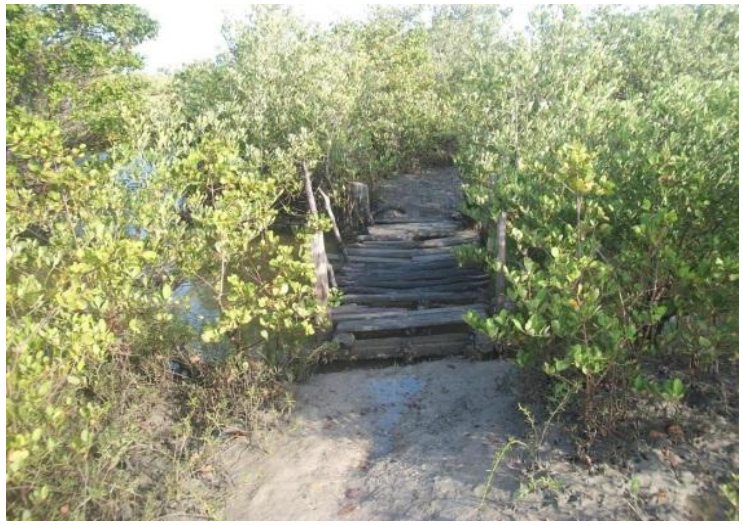

Figura 6 - Trilha ecológica pelas gamboas em Curral Velho, Acaraú-CE. Foto: Loureiro, 2015.

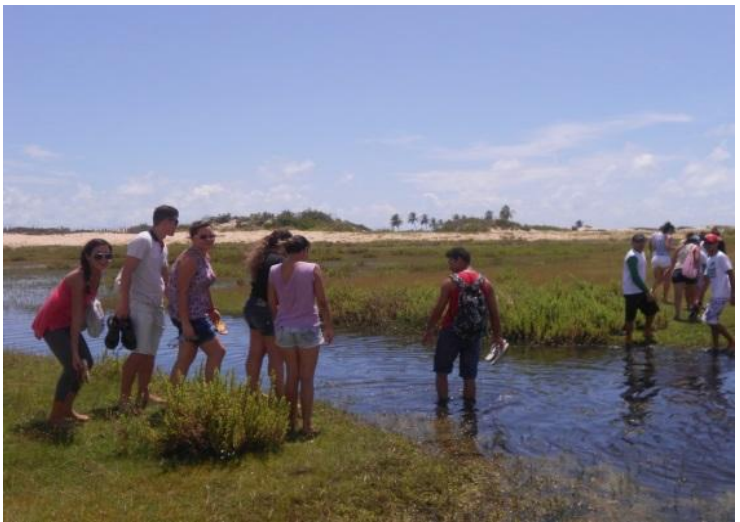

Figura 7 - Trilha ecológica na Prainha do Canto Verde, Beberibe-CE. Foto: Loureiro, 2016.

As comunidades destacam em suas falas que o Turismo Comunitário é uma alternativa de geração de renda e empregos que complementa e se integra às Ciência e Sustentabilidade - CeS / Juazeiro do Norte, v. 3, n. 1, p. 58-73, jan/jun 2017 
atividades extrativistas existentes. O pescado local é escolhido e servido aos visitantes, os produtos feitos pelas rendeiras e 0 artesanato produzido por sementes locais são vendidos nas pousadas e associações.

As infraestruturas em geral são simples e se adaptam à dinâmica dos ecossistemas. Em Tatajuba, barracas pertencentes aos moradores locais funcionam como pequenos negócios turísticos (Figura 8). Tais estruturas migram de acordo com a dinâmica dos ambientes.As barracas se localizavam na Lagoa da Torta, porém com o ressecamento do ambiente, foram transferidos para o Lago Grande, outro recurso hídrico também localizado na área da comunidade (Figura 9).

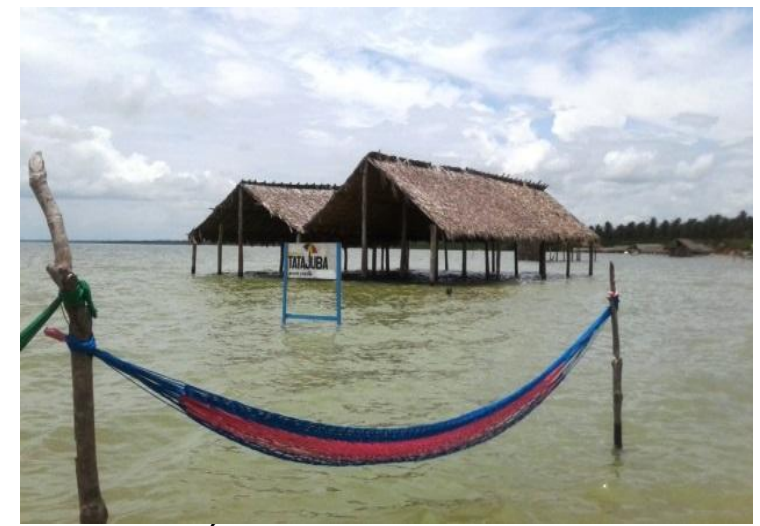

Figura 8 - Área para banhistas no Lago Grande em Tatajuba, Camocim-CE. Foto: Loureiro, 2017.

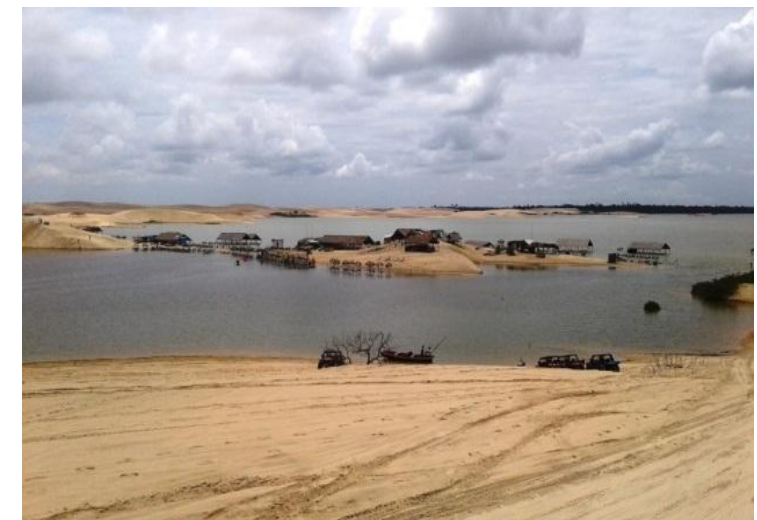

Figura 9 - Barracas no Lago Grande em Tatajuba, Camocim-CE. Foto: Loureiro, 2017.

\section{DESAFIOS E DIFICULDADES AO FORTALECIMENTO DO TURISMO COMUNITÁRIO NA ZONA COSTEIRA CEARENSE}

Apropriar-se das práticas do Turismo Comunitário requer comprometimento à execução de seus reais objetivos e manutenção de valores. A prática não deve representar mudanças nos moldes de desenvolvimento tradicional que já possuem.

O fortalecimento desta atividade, no entanto, enfrenta dificuldades. A Rede Tucum juntamente com o Instituto Terramartrabalham no sentido de apoiar o TBC nas comunidades pertencentes à Rede, no entanto esbarram nos interesses de especuladores imobiliários. Dentre os desafios identificados foram verificados questões como a regularização da terra e, sobretudo, a garantia da posse e do uso;os conflitos relacionados à especulação imobiliária; regulamentaçãopara possibilitar o uso sustentável de Unidades de Conservação;e o fortalecimento de políticas públicas voltadas ao TBC. 
No que se refere à regularização da terra é perceptível e geral o sentimento de apreensão. Tal fato relaciona-se diretamente com a questão da especulação imobiliária que, por meio da grilagem de terras,desencadeiam conflitos constantes com os moradores locais.

$O$ fato de localizarem-se em zonas costeiras com relevante potencial paisagístico, faunístico e de flora, faz com que algumas áreas sejam decretadas Unidades de Conservação. No entanto, ainda há a necessidade de se ajustar algumas práticas aos usos compatíveis com os potenciais e limitaçãoes dos ecossistemas.

A Comunidade da Tatajuba, por exemplo, insere-se em uma APA criada por decreto municipal, porém inconsistências na delimitação do perímetro desta unidade de conservação, bem como a inexistência de um plano de manejo e de conselho consultivo,vem facilitando a entrada de especuladores imobiliários que buscam expropriar os moradores nativos para a colocação de empreendimentos turísticos. No momento, a comunidade vem se mobilizando para que seja criada uma Reserva de Desenvolvimento Sustentável (RDS) na área, pois além de buscarem a preservação dos ecossistemas, veem na criação dessa Unidade de Conservação uma possibilidade de proteger o território de especuladores imobiliários.

No que se refere à questão de políticas públicas voltadas ao apoio da atividade, percebe-se que há carência de ações, e de uma forma geral, de políticas em todos os âmbitos. É importante salientar que, em geral, o TBC se desenvolve em áreas onde as políticas públicas não atendem as necessidades da população, porém não cumpre essa carência. $O$ apoio existente à prática é apenas o recebido pela articulação na Rede Tucum.

\section{CONSIDERAÇÕES FINAIS}

As atividades turísticas tradicionais, imobiliárias e industriais no litoral cearense têm se apropriado de forma desordenada e, na maioria das vezes, degradante, dos ecossistemas litorâneos, alterando e desarticulando a dinâmica ambiental e social dos espaços dos quais se apropriam.

O Turismo Comunitário praticado na zona costeira cearense veio responder a duas demandas: a turística, que anseia por um turismo mais voltado para os 
aspectos socioculturais e ambientais das comunidades receptoras, e, sobretudo, a da necessidade de diversificar suas atividades econômica.

Nesse contexto, o Turismo Comunitário expõe sua responsabilidade social e ambiental nas áreas onde se insere, respondendo à demanda humana por turismo e lazer, e oferecendo de forma sustentável a prestação desse serviço, diferentemente da grande maioria das atividades econômicas. Proporciona um relacionamento mais autêntico entre o visitante, o local e a comunidade, e possibilita um conhecimento e conscientização acerca da importância da preservação dos ecossistemas litorâneos, por meio da educação ambiental trabalhada nos roteiros.

Em relaçãoa questão econômica, a prática do TBC insere uma outra opção de geração de renda, além de possibilitar o engajamentodos habitantes no controle efetivo das transformações em curso nos territórios onde vivem.

Esse estudo buscou sintematizar as práticas e contextos existentes nas comunidades praticantes do turismo comunitário, avaliando como a imersão nesta prática pode diversificar a economia local, preservar o meio ambiente e desenvolver relações de proximidade e respeito com os turistas/visitantes.Porém, é importante salientar que mesmo apresentando o perfil de três comunidadesdistintas, não podemos generalizar as demais, mas apenas compreender alguns aspectos relevantes e comuns a todas, a exemplo dos conflitos relacionados à especulação imobiliária na zona costeira cearensee a ausência do fomento público para incremento das práticas ancoradas no turismo comunitário.

\section{REFERÊNCIAS}

BRASIL. Ministério do Turismo. Dinâmica e diversidade do turismo de base comunitária: desafio para a formulação de política pública. Brasília: Ministério do Turismo, 2010.

CAMURÇA, S. Certificação do Turismo um Desafio para o Turismo. In: LIMA, L. C.; CORIOLANO, L. N. M. T. (Orgs.) Turismo e Desenvolvimento Social Sustentável. Fortaleza: EdUECE, 2003. p. 171-174.

CORIOLANO, L. N. M. T. O Turismo de Base Local e o Desenvolvimento na Escala Humana. In: LIMA, L. C.; CORIOLANO, L. N. M. T. (Orgs.) Turismo e

Desenvolvimento Social Sustentável. Fortaleza: EdUECE, 2003. p. 60-71. 
CORIOLANO, L. N. M. T. (Org.) Arranjos produtivos locais do turismo comunitário: Atores e cenários em mudanças. Fortaleza: EdUECE, 2009.

CORIOLANO, L. N. M. T. O turismo comunitário no nordeste brasileiro. In:

BARTHOLO, R; D. G.; SANSOLO, D. G.; BURSZTYN, I.(Orgs.). Turismo de Base Comunitária: diversidade de olhares e experiências brasileiras. Rio de Janeiro, RJ: Letra e Imagem, 2009. p. 289-301.

DANTAS, E. W. C. "LITORALIZAÇÃO" DO CEARÁ: Fortaleza, da "Capital do Sertão" à "Cidade do Sol". In: SILVA, J. B.; DANTAS, E. W. C.; ZANELLA, M. E.; MEIRELES, A. J. A (Orgs.). Litoral e Sertão, natureza e sociedade no nordeste brasileiro. Fortaleza: Expressão Gráfica, 2006. p. 245-252.

LOUREIRO, C. V.; GORAYEB, A. O Turismo comunitário como alternativa para a preservação dos ecossistemas litorâneos: o caso da Comunidade de Curral Velho, Acaraú-CE-Brasil. Revista de Turismo Contemporâneo - RTC, v. 1, n. 1, 2013, p.1-17.

LÓPEZ-GUZMÁN, T.; BORGES, O.; CASTILLO-CANALEJO, A.M. Desarrollo económico local y turismo comunitarioen países envías de desarrollo: Unestudio de caso. Revista Omnia, v. 17, n. 3, 2011, p. 113-130.

MARTINS, R. (Org.) Caderno de Normas da Rede Tucum - Rede Cearense de Turismo Comunitário. Fortaleza: Instituto Terramar, 2013.

REDE Cearense de Turismo Comunitário. Disponível em: <http://www.tucum.org/> Acesso em: 22 mai. 2017, 12:16:00.

RODRIGUES, A. B. (Org.). Ecoturismo no Brasil: possibilidades e limites. São Paulo, SP: Contexto, 2003.

TOSUN, C. Challengesofsustainabletourismdevelopment in thedeveloping world: the case ofTurkey. Tourism management, v. 22, n. 17, 2001, p. 289-303.

World Tourism Organization. Tourism 2020 vision. 2012. Disponível em: < http://< www.unwto.org/facts/eng/vision.htm > Acesso em: 14 jun. 2017, 15:30:30.

ZAOUAL, H. Do turismo de massa ao turismo situado: quais as transições? In:BARTHOLO, R; D. G.; SANSOLO, D. G; BURSZTYN, I. (Orgs.). Turismo de Base Comunitária: diversidade de olhares e experiências brasileiras. Rio de Janeiro, RJ: Letra e Imagem, 2009. p. 55-75 